\title{
TRENDS AND VULNERABILITY ASSESSMENT OF METEOROLOGICAL AND AGRICULTURAL DROUGHT CONDITIONS OVER INDIAN REGION USING TIME- SERIES (1982-2015) SATELLITE DATA
}

\author{
Rituparna Das ${ }^{1, *}$, Prabir Kumar Das ${ }^{2}$, Sounmya Bandyopadhyay ${ }^{2}$, Uday Raj ${ }^{3}$ \\ ${ }^{1}$ TERI School of Advanced Studies, New Delhi, India- rituparnadas030@gmail.com \\ ${ }^{2}$ Regional Remote Sensing Centre-East, NRSC, ISRO, Kolkata, West Bengal, India \\ ${ }^{3}$ Regional Centres, NRSC, ISRO, Hyderabad, Telangana, India
}

Commission III, WG III/10

\begin{abstract}
KEY WORDS: Meteorological Drought, Agricultural Drought, Trends, Vulnerability, Standardized Vegetation Index, Standardized Precipitation Index.
\end{abstract}

\begin{abstract}
:
The vulnerability and trends of meteorological as well as agricultural drought conditions over Indian region was studied using longterm (1982-2015) gridded precipitation and time-series normalized difference vegetation index (NDVI) data. The Climate Hazards Group Infra-Red Precipitation with Station (CHIRPS) precipitation data ( $\sim 5 \mathrm{~km})$ was used to compute Standardized precipitation index (SPI) at 3-month time scale for Indian summer monsoon season (June-September). Subsequently, the long-term Global Inventory Modelling and Mapping Studies (GIMMS) time-series NDVI data $(\sim 8 \mathrm{~km})$ was interpolated at daily scale and smoothened using Savitzky and Golay filtering method. Further, the time-series NDVI data was transformed into several phenological parameters using threshold and derivative approach. As integrated NDVI, i.e. the area under seasonal NDVI curve, is able to represent the anomalies in seasonal agricultural production, it was transformed into standardized vegetation index (SVI) using empirical distribution. Several drought parameters, e.g. magnitude and extent, were computed at district level based on the SPI and SVI values, where values with SPI or SVI less than minus one was considered as meteorological and agricultural drought year, respectively. The trends of drought magnitude and extent for both the meteorological and agricultural drought were estimated using Sen's slope. The direction of trends and magnitude were found to be varying spatially across different parts of Indian region. Further, the mean SPI/SVI values along with drought frequency were utilized to categorize entire Indian agricultural area into different vulnerable zones during three decades separately. The overall drought vulnerability was found to be decreasing over time.
\end{abstract}

\section{INTRODUCTION}

Drought is a climatic phenomenon that affects the natural variability of the climate system. In terms of precipitation and temperature regimes, occurrence of drought can be possible in all regions of the entire world (Hao et al. 2013). Even in the present day, though there are advanced technologies and communication no country can effectively claim as immune to the effect of drought.

Droughts are slow-onset phenomenon; especially extensive event of nature which can affect a region for weeks, months or may be years. Because of this creeping phenomenon, drought can be the cause of prompting mass migration, environmental degradation and famine-like situation (Rojas et al. 2011). One of the most popular perceptions of drought is meteorological drought phenomenon. This kind of phenomenon can be occurred due to lack of expected precipitation. However, there is no particular definition to describe drought and the impact on a region, meteorological drought is generally occurred for rainfall deficiency from the average condition (WenWang et al., 2016). In case of agricultural drought, it implies the unavailability of soil moisture for crop growth (Shaw et al. 2017). There are more than half of professions in India directly or indirectly dependent on the agriculture, though most of the areas in India are marked as drought prone. South-west monsoon from June to September is the reason, that India receives more than $70 \%$ rainfall every year (Mishra et al., 2010).
In the year 1967, first Gibbs and Maher established the rainfall deciles theory. For meteorological drought estimation, standardized precipitation index (SPI) is a popular and powerful tool among the various indexes (McKee et al. 1993). Using Standardized Precipitation Index and Standardized Flow Index (SFI) Wen at al. in 2011 describe meteorological drought history for long-term years 1889 to 2007 in New South Wales, Murrumbidgee Catchment and Australia. Rainfall Anomaly Index calculates meteorological drought on weekly, monthly or annual time scale (Von et al. 1965). As per the literature review, usually meteorological drought and hydrological drought are the vital reason of agricultural drought. In 1980 and early 1990s agricultural drought across Africa have affected my countries, probably the most shocking in recent history (Rojas et al., 2011). Agricultural drought is the most aspect for drought monitoring but it is far more complicated for some investigations (Palmer, 1965).

The present study intends to analyse the vulnerability and trends of meteorological as well as agricultural drought conditions over Indian region using long-term (1982-2015) gridded precipitation and time-series normalized difference vegetation index (NDVI) data.

\section{DATA SETS}

In the present study, major three types of database have been used, viz. (i) GIMMS NDVI, (ii) CHIRPS and (iii) Land cover

\footnotetext{
* Corresponding author
} 
data. GIMMS is the Global Inventory Modelling and Mapping Studies. NDVI datasets are available from 1981 to 2015 with $1 / 12$ degree $(\sim 8 \mathrm{~km})$ spatial resolution and 15 days temporal resolution. In the present study, GIMMS data sets from 1982 to 2015 has been extracted for Indian region and for these 34 years period total 828 layers has been processed. (ii) CHIRPS data is the long-term precipitation data, downloaded from Climate Hazards Group InfraRed Precipitation with Station. This data provides long-term information on precipitation in global scale with $0.05^{\circ}(\sim 5 \mathrm{~km})$ spatial resolution. Total 408 layers of CHIRPS data has been used for period of entire 34 years (1982 to 2015). (iii) Land cover data with $8 \mathrm{~km}$ resolution, downloaded from ftp://glcf.umd.edu.

\section{METHODOLOGY}

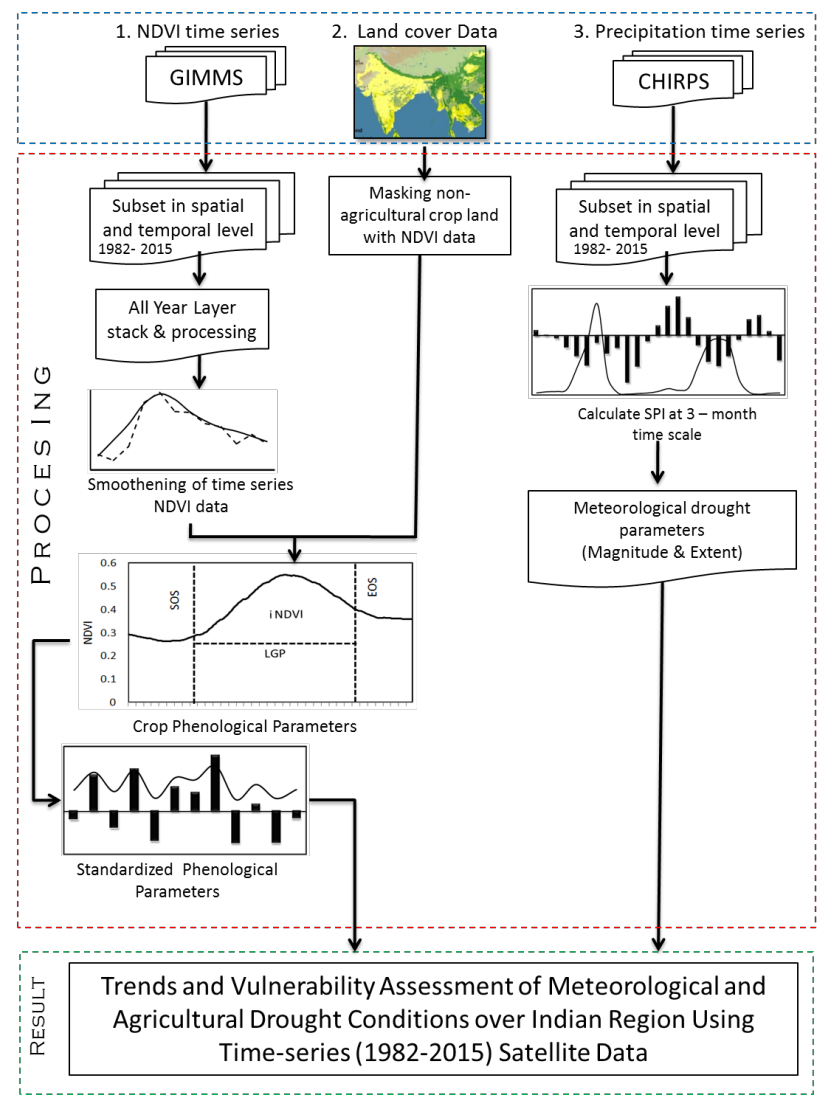

Figure 1 the schematic diagram of the overall methodology

\subsection{Interpolation and smoothening of NDVI data}

The 15-day NDVI data was transformed into daily NDVI using interpolation method to estimate the crop phenological stages more accurately. To eliminate the noise, NDVI datasets were filtered with Savitzky and Golay (1964) method. In the case of NDVI data smoothening specifying degree of smoothening polynomial plays a determine role, which is the range of 2 to 4 . Here the 2nd order polynomial with seven windows filter size was used. The general equation, which simplifies the leastsquare method of NDVI time series smoothing,

$$
Y_{j}^{*}=\frac{\sum_{i=-m}^{i=m} C_{i} Y_{j+i}}{N}
$$

Where, $Y$ refers NDVI value, $Y^{*}=$ resultant NDVI values, $\mathrm{C}_{\mathrm{i}}$ is the $i^{\text {th }}$ NDVI coefficient value of the filtered smoothing window, $N=$ number of convoluting integers which is equal to smoothing window $(2 \mathrm{~m}+1), \mathrm{j}$ is running index.

\subsection{Extraction of Crop Phenology}

Using the combination of threshold and derivative approaches different crop phenological stages were extracted from timeseries filtered NDVI data. The time-series NDVI daily data was utilized to estimate four (04) major phenological parameters. These parameters are as follows,

SOS: SOS refers to the start of growing season of a particular crop. In the present study, the SOS was estimated using the maximum rate of NDVI changes between sowing of that particular crop and peak vegetation rate.

EOS: EOS is the end of growing period of a particular crop. Similar as SOS, the EOS was estimated based on the maximum rate of decrees in NDVI values between peak vegetation and harvesting date of that particular crop.

LGP: LGP defines length of growing period of the crop. Length of growing period considered the period between SOS and EOS.

Integrated NDVI: Integrated NDVI represents the integrated value of daily time step NDVI from SOS to EOS.

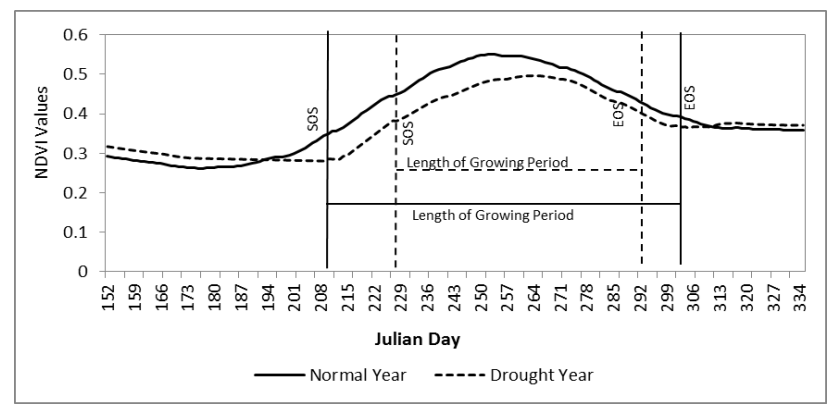

Figure 2 The NDVI profiles along with phenological parameters for drought and normal years

The Figure (2) represents the NDVI profiles along with different phenological parameters for normal year and drought year, respectively. NDVI data has been shown from June to November as the present study confined to kharif season only. As the drought leads to delay in crop sowing activities, the sowing date has shifted from mid-week of June to July last week. It is interesting to note that the date of harvesting remains almost similar for both the year. Due to delay in the sowing day, the length of growing period was compressed by one or half month. As a result, the SOS was delayed and EOS has advanced, which lead to shortened effective crop growing period and a significant decrease in the integrated NDVI values. According to the observations along with literature review, it can be inferred that the drought may directly affect the integrated NDVI, representing the reduction in crop production.

\subsection{Generation of standardization of vegetation index:}

To generate standardized vegetation index (SVI) the integrated NDVI has been utilized. In the present study, standardization of integrated NDVI has been adopted which is similar to standardized precipitation index (SPI). An empirical approach was adopted to derive the marginal probability of the timeseries crop phenological parameter, i.e. integrated NDVI. This approach uses univariate form of Gringorten plotting position 
formula (Hao et al. 2013). This plotting position formula can be expressed as:

$$
P\left(x_{i}\right)=\frac{i-0.44}{n+0.12}
$$

Where, $\mathrm{i}=$ rank of the smallest observed values, $\mathrm{n}=$ total number of observations. Similar to SPI, the values of this standardized index are ranging from -4.0 to +4.0 , where the negative values represent the drought condition and vice-versa. In the present study, this standardized integrated NDVI is named as standardized vegetation index (SVI).

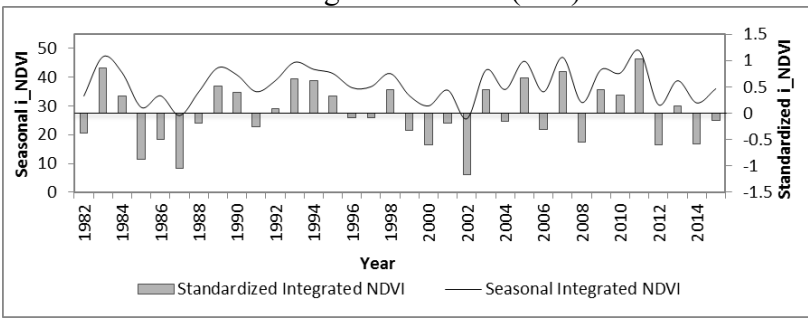

Figure 3 The NDVI profiles along with phenological parameters representing seasonal values and standardized values

From the figure (3), it can be observed that effective ranges of the standardized index are more than the normal values of the phenological parameters. Moreover, it can be said that this standardized index can able to discriminate the agricultural drought year and non-drought year more effectively. The agricultural drought magnitude and extend was calculate separately using the SVI values.

\subsection{Generation of Standardized Precipitation Index}

SPI has been calculated at different time-scales, i.e. 3, 6 and 12 month, for monsoon season from 1982 to 2015. To define and monitoring drought, SPI plays an important role. SPI can be calculated using the following equation:

$$
S P I=\frac{\left(x_{i j}-X_{i m}\right)}{\sigma}
$$

Where, $\mathrm{X}_{\mathrm{ij}}=$ seasonal precipitation at the $\mathrm{i}^{\text {th }}$ rain-guage station, $j^{\text {th }}$ observation. $X_{i m}=$ long term seasonal means and $\sigma$ is the standard deviation. According to literature review, SPI value reaches -1.0 , drought event starts and positive SPI value, it ends (Das et al. 2015).

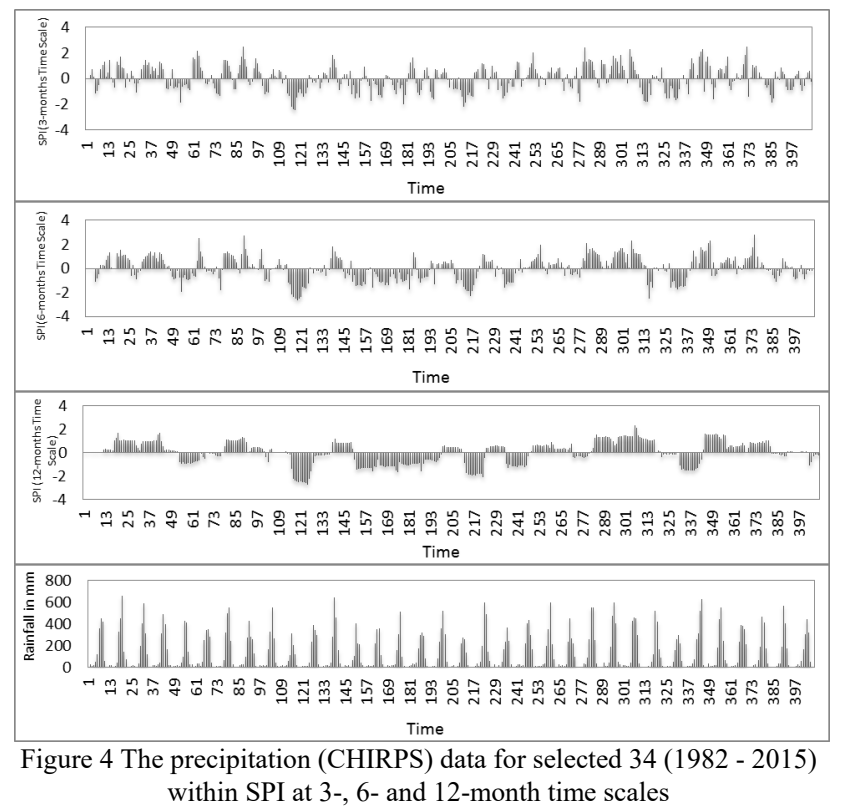

\subsection{Generation of Meteorological Drought Parameters:}

In the present study, SPI value at 3-month time-scale has been used to calculate drought magnitude and occurrence of drought using the above-mentioned threshold. Any event with SPI value less than threshold was considered as the occurrence of drought, whereas, the accumulative value of SPI during the drought months for each year was considered as magnitude (Vicente et al., 2014, Das et al. 2015). Using the drought occurrence, the percentage of drought-affected area for each district was calculated. Drought extent is the percentage of geographic area affected by drought.

\subsection{Trend Analysis:}

The anomalies of seasonal drought parameters were calculated using the absolute deviation from their long-term average (Das et al. 2015). In the present study, over the time series anomalies trend analysis was performed at district level. The direction of trend of seasonal drought parameters and calculated drought indexes during the monsoon season was estimated using nonparametric Mann-Kendall test. The Mann-Kendall method finds for a trend in time-series data without specifying whether the trend is linear or non-linear (Das et al. 2014). The Sen's slope was used to find the magnitude of the trends.

Sen's slope estimator is one of the best non-parametric trend operators and it is free from gross data error (Sen., 1968).

3.6.1 Vulnerability Assessment: In the present study, the mean SPI and SVI values along with drought frequency were utilized to categorize entire Indian agricultural area into different vulnerable zones during three decades separately, viz. 1982-1992, 1993-2002 and 2003-2015. To prepare vulnerability map median threshold method has been considered. The grid with drought frequency more than its median will be considered as high frequency or vice versa. For example, if the median value is 2.5 , any frequency value above 2.5 during the 10 years will be considered as high frequency or else low frequency. Similarly, the SPI or SVI values greater than median value for a given year will be considered as high mean and vice versa.

Based on these two parameters (frequency and mean) vulnerability had been calculated using the following criteria, High Frequency and High Mean > Highly Vulnerable Low Frequency and Low Mean $>$ Low Vulnerable Low Frequency and High Mean $>$ Moderately Vulnerable High Frequency and Low Mean $>$ Moderately Vulnerable

\section{RESULTS \& DISCUSSION}

It can be seen that over western parts of India and peninsular region the mean SPI values during 1982- 1992 were -2.5 to <7.5 (Figure 5). Whereas, during 1993- 2002 and 2003-2015 it was found to be decreasing (Figure 5). Similar kinds of observations were recorded in case of SVI also during the last three decades. In the case of standardized vegetation index, the mean SVI values were very high in the western region of India. In the southern region, it was comparatively low. It indicates that the western region was more drought prone than southern region. During 2002 to 2015 (Figure 6) it can be seen that along the Indo-Gangetic plain the mean SVI value is higher. 

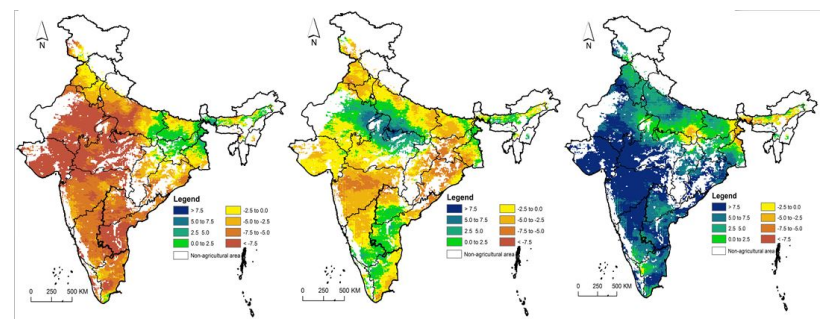

Figure 5 Mean SPI values from 1982-1992, 1993-2002, 2003-2015

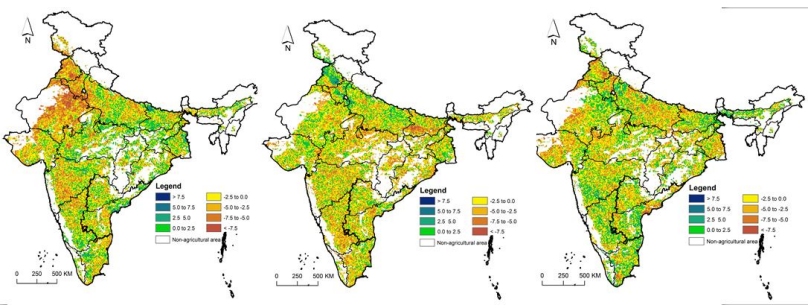

Figure 6 Mean SVI values from 1982-1992, 1993-2002, and 2003-2015 Legend

$$
\begin{aligned}
& >7.5 \\
& 5.0 \text { to } 7.5 \\
& \begin{array}{l}
\hline 2.55 .0 \quad \square-2.5 \text { to } 0.0 \\
0.0 \text { to } 2.5 \square-5.0 \text { to }-2.5 \\
\square \text { Non-agricultural area }
\end{array}
\end{aligned}
$$

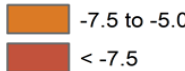

Similar to SVI and SPI, the frequency of drought was also found to be decreasing during the last three decades. During 1982-1992 (Figure 7) the frequency of meteorological drought was very high (around5), specifically in Madhya Pradesh, Rajasthan and Gujarat. Meteorological drought frequency decreased in those regions during 1993-2002 (Figure 7). In 2003 to 2015, (Figure 7) meteorological drought frequency was found to be further decreased.

In case of agricultural drought, high frequency can be noticed during 1982-1992 in Rajasthan and Madhya Pradesh region (Figure 8). The frequency was found to be decreasing over Rajasthan and Madhya Pradesh during later two decades, but it was observed that over central India and Indo-Gangetic plain it was increasing during 1993-2002 and 2003-15, respectively.
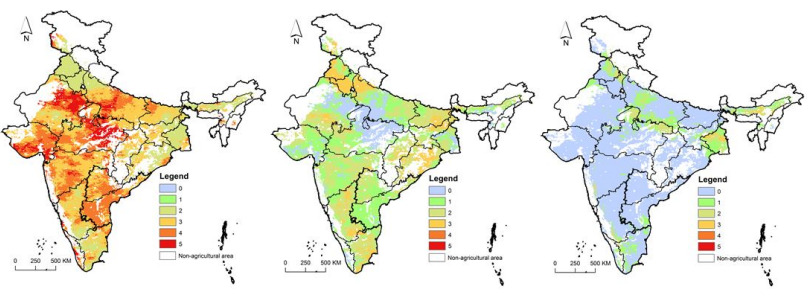

Figure 7 Frequency of Meteorological drought from 1982-1992, 19932002 and 2003-2015
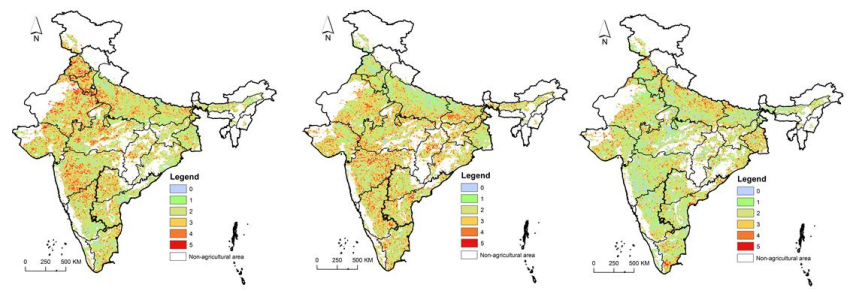

Figure 8 Frequency of Agricultural drought from 1982-1992, 1993-2002 and 2003-2015

\section{Legend}

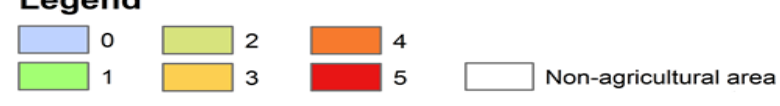

\subsection{Trend Analysis}

4.1.1 Trends of Phenological Parameters: In the case of start of growing period, most of the regions have increasing trend representing advanced SOS. Some isolated districts in northern region are found no trend for SOS. Some district over peninsular India, the trends were found to be significantly negative at 95\% confidence limit (Figure 9).

Negative trend has been found for EOS over the eastern coast of the peninsular region. Significant regions with positive trends were found over major parts of the Indian region, which is more or less similar to SOS (Figure 10). In the case of LGP, in major parts of the country negative trends were observed. Some isolated districts in coastal region were found with significant positive trends at $95 \%$ confidence limit (Figure 11). For integrated NDVI, negative trends were found along the Western Ghats, Eastern coastal plain and some districts over West Bengal, Bihar and Madhya Pradesh (Figure 12).

4.1.2 Trends of SPI Parameters: The spatial variability of temporal trends of meteorological drought over India has been represented at district level during the monsoon season.

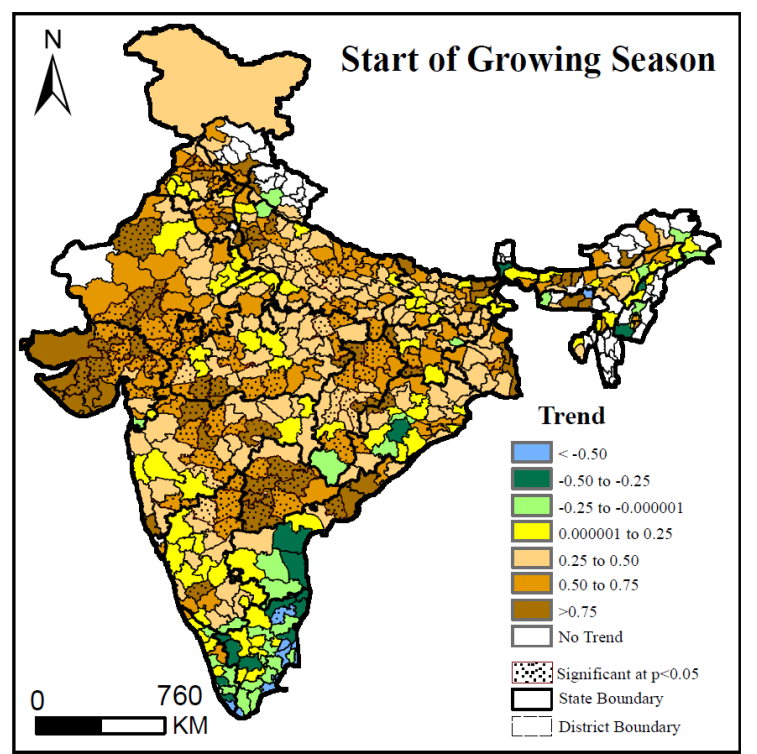

Figure 9 Trends of start of growing period for Kharif crop during 19822015 . 


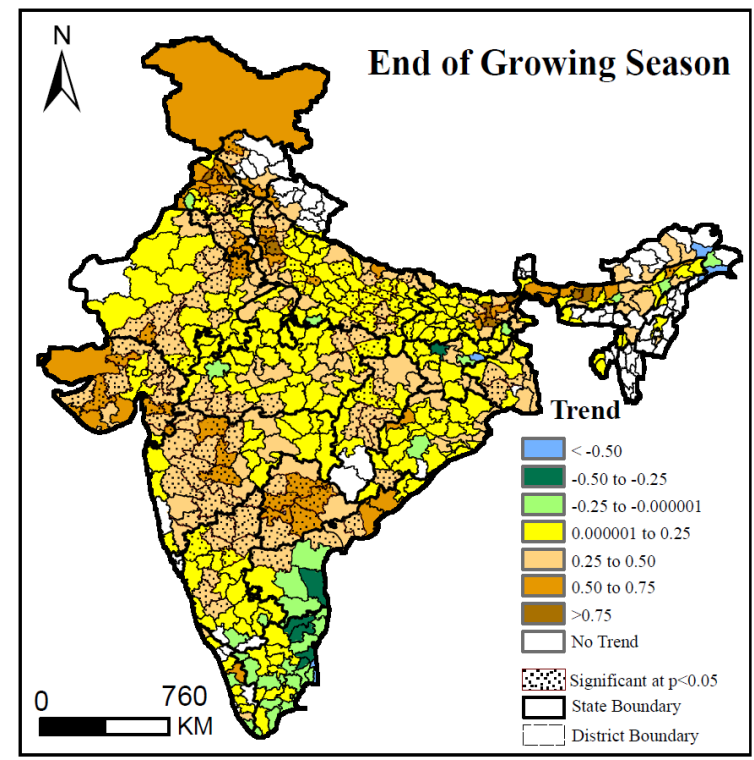

Figure 10 Trends of end of growing period for Kharif crop during 19822015 .

Drought magnitude generally explains the intensity of the drought (Das et al. 2015). In the case of magnitude of meteorological drought trend, almost $80 \%$ of the study area showed no trend. The most of the districts with the negative trend was found over Maharashtra, central and southern parts of the India (Figure 13). Some isolated districts of zero to positive trend of meteorological drought were found. Positive trend was found over Pune district in Maharashtra, South 24-Parganas of West Bengal, two districts of Tamil Nadu. Drought extend defines the percentage of affected drought area. In the case of meteorological drought extend most of the area was found under no trend whereas some isolated patches of negative trend were observed in the southern part and Madhya Pradesh (Figure 14).

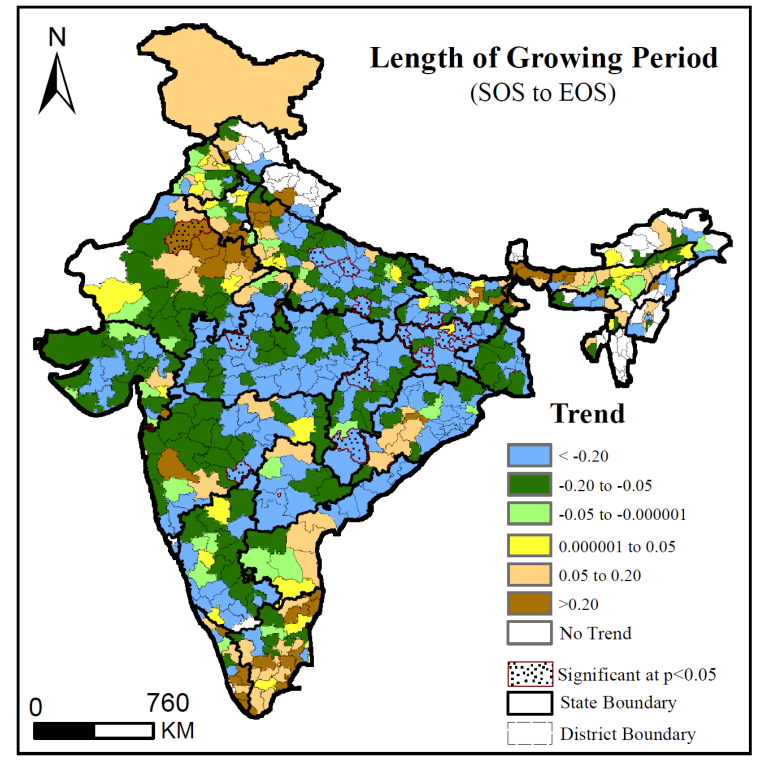

Figure 11 Trends of length of growing period for Kharif crop during 1982-2015.

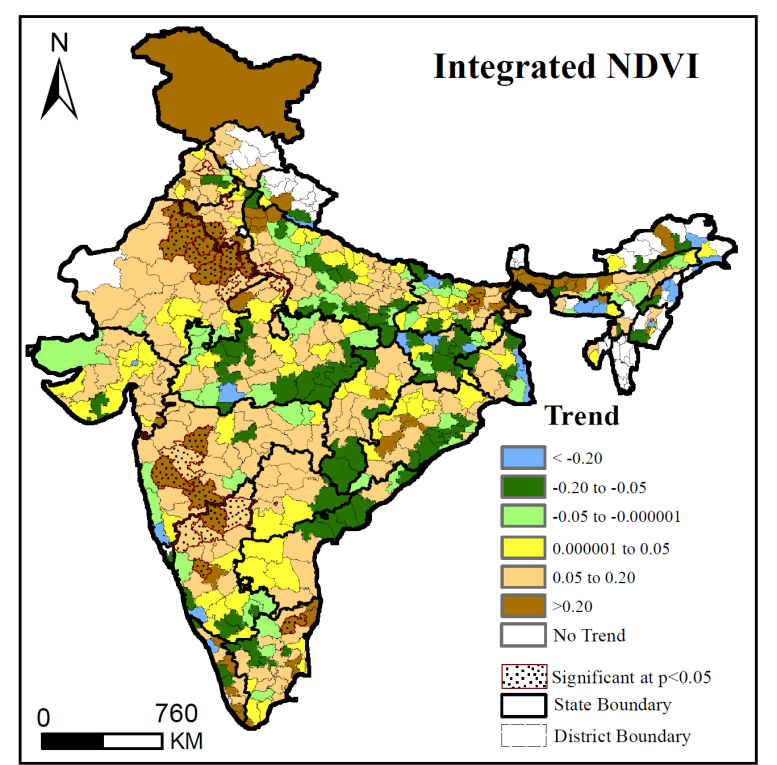

Figure 12 Trends of integrated NDVI for Kharif crop during 1982-2015.

4.1.3 Vulnerability Analysis: In most of the parts of Indian agricultural area the meteorological drought vulnerability was found to be high, whereas low vulnerability was observed over northeast region along with parts of Bihar, Jharkhand, Haryana, Punjab and West Bengal during 1982-1993 (Figure 15). The moderate vulnerable areas were confined in lower parts of Haryana and Punjab along with Bihar and eastern parts of Uttar Pradesh. It is observed that during 1993 to 2003 the overall vulnerability has decreased in most parts of Indian region, except Haryana, Punjab, Orissa, Jharkhand and parts of Bihar (Figure 16), whereas moderate vulnerability was found over entire Maharashtra and parts of Chhattisgarh. During 20032015, the entire India was found to be under low vulnerability except some patches over north-eastern region and West Bengal.

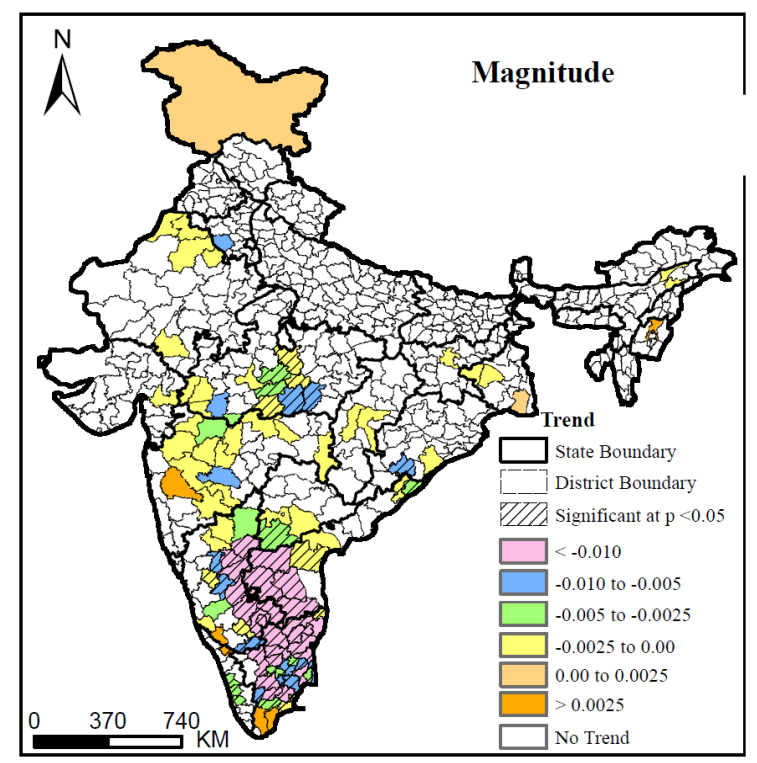

Figure 13 Trends of meteorological drought magnitude during 19822015 


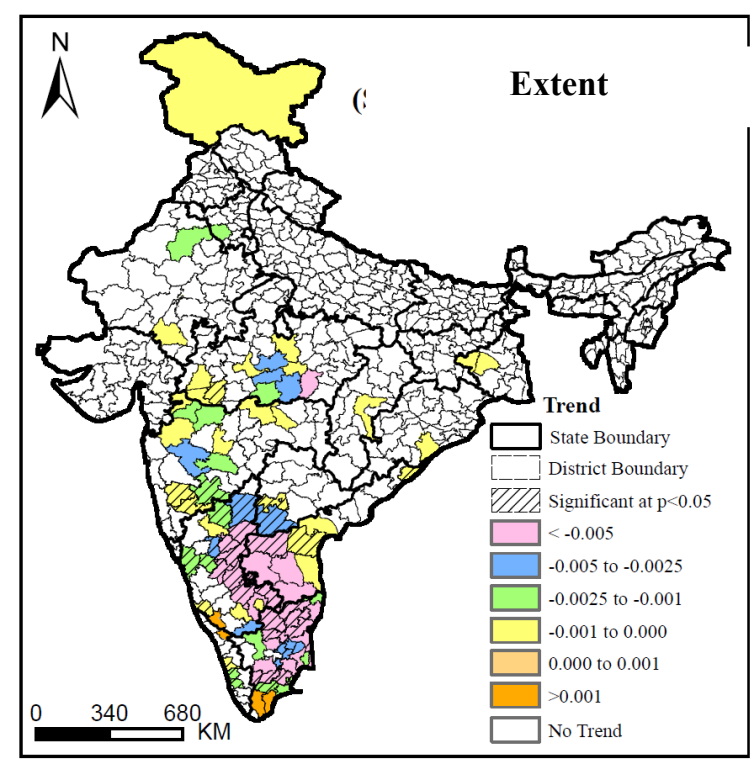

Figure 14 Trends of meteorological drought extent during 1982-2015.

In case of agricultural drought vulnerability, high vulnerable areas was found over Rajasthan, Punjab, Haryana and parts of Maharashtra, Karnataka, Andhra Pradesh, Uttar Pradesh and Tamil Nadu, whereas in rest of the areas low vulnerability was observed during 1982-1992 (Figure 18). During the last two decades, i.e. 1993-2002 and 2003-2015, the overall vulnerability was found to be decreasing in most parts of India, whereas it was found to be higher in parts of Karnataka, Uttar Pradesh and Bihar (Figure 19 \& Figure 20).

\section{CONCLUSION}

The major objective of the present study was to analyse the trend and vulnerability of the meteorological and agricultural drought over Indian agricultural region during last three decades, i.e. 1982 to 2015. The mean drought value (for meteorological and agricultural both) and drought frequency were found to be

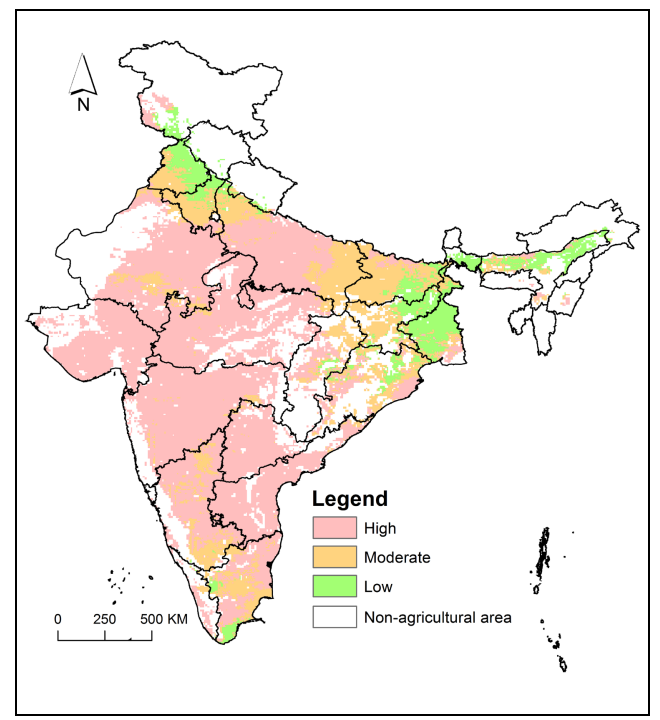

Figure 15 Vulnerability Map of Meteorological Drought During 19821992.

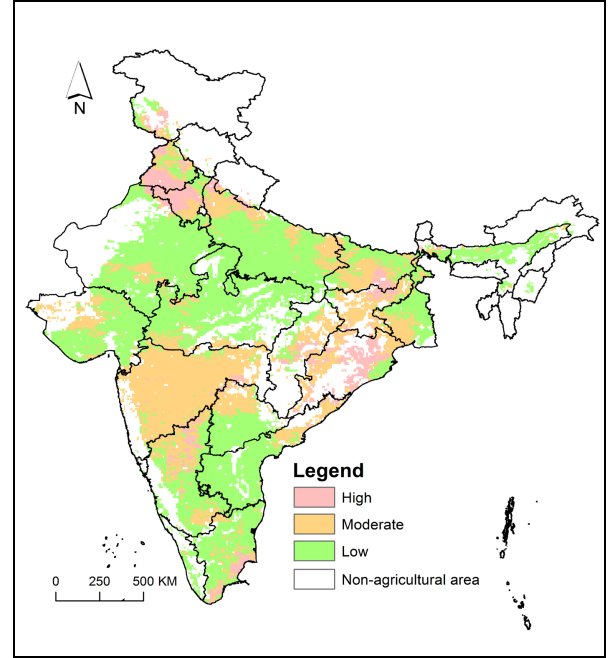

Figure 16 Vulnerability Map of Meteorological Drought During 19932002.

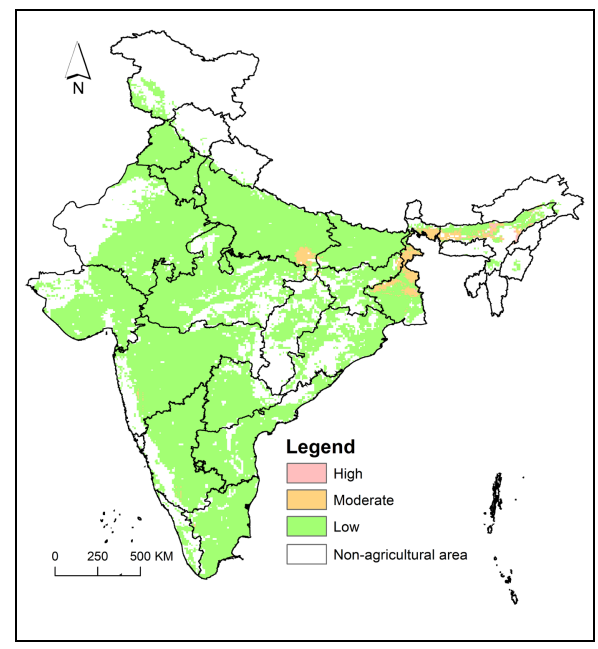

Figure 17 Vulnerability Map of Meteorological Drought During 20032015.

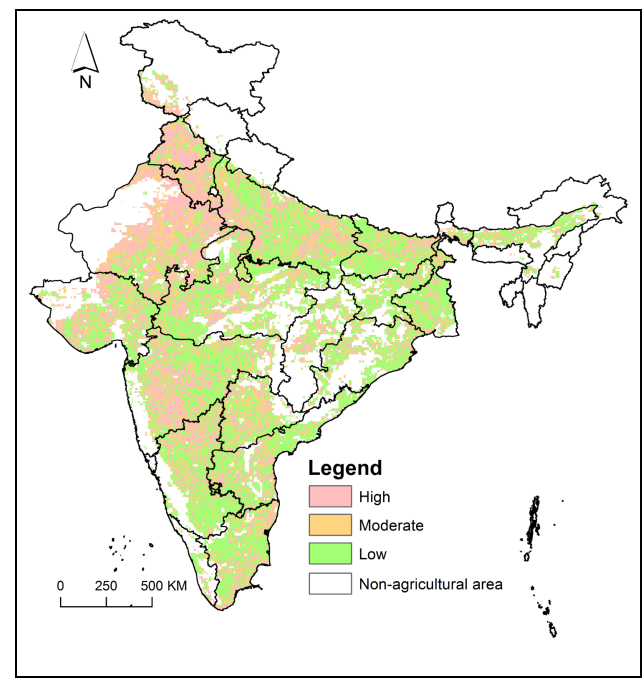

Figure 18 Vulnerability Map of Agricultural Drought During 19821992. 


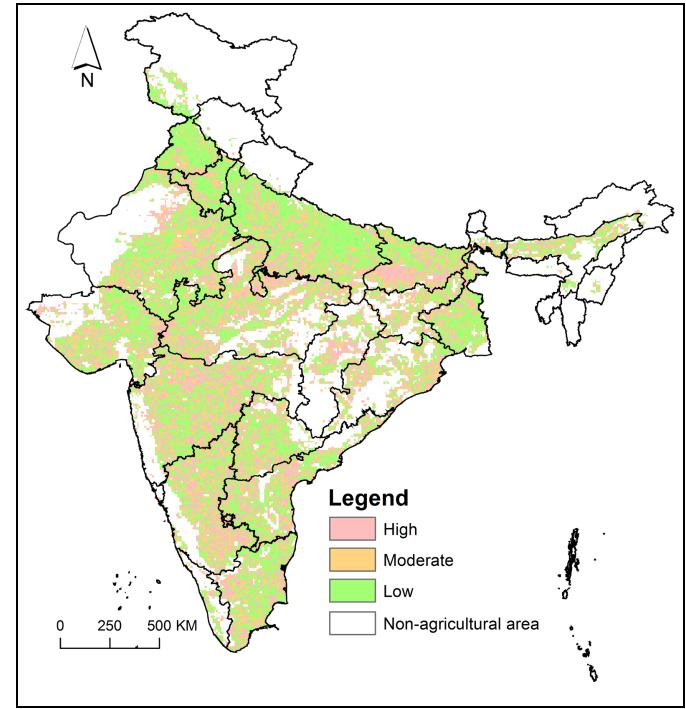

Figure 19 Vulnerability Map of Agricultural Drought During 19932002.

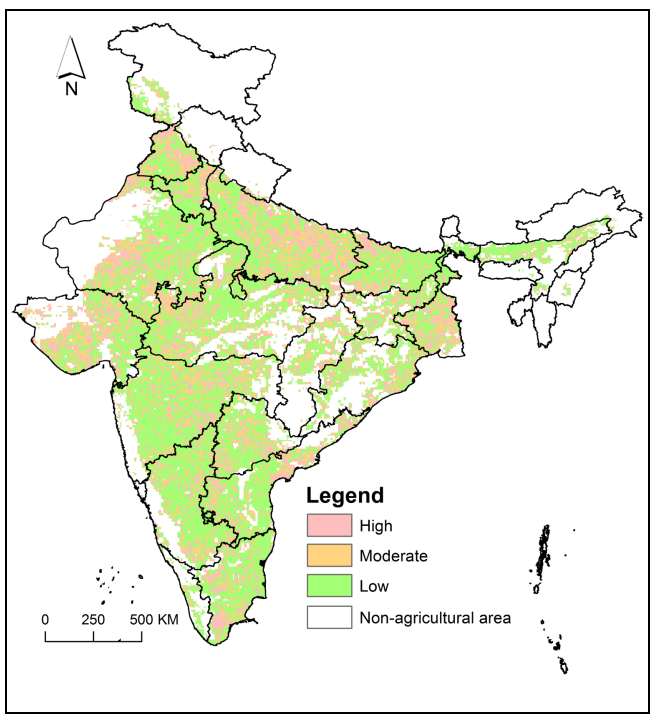

Figure 20 Vulnerability Map of Agricultural Drought During 20032015.

Decreasing during the last three decades. The meteorological drought frequency was very high over western India during first decade of the study period, whereas in next two decades, i.e. 1993-2002 and 2003-2015, it was found to be decreasing. Hence, as a resultant the trend and vulnerability were also found to be decreasing for meteorological drought. In the case of agricultural drought, it was noticeable that during 1982-1992 vulnerability was higher in most of the north-western states. During the last two decades of the study period, some parts of southern Karnataka, Bihar and Uttar Pradesh, the vulnerability was found to increasing. Positive trends of start and end of crop growing stages were found in most parts of the country, except parts of peninsular India. However, the trends of length of growing period showed that the crop duration are significantly decreasing over most parts of the country. The trends of crop production, in terms of integrated NDVI, was found to positive in major parts of the study area, except some isolated patches over central India along with western and eastern coast.

\section{REFERENCES}

Beguer'1a, S., Vicente-Serrano, S. M., Reig, F., \& Latorre, B. (2014). Standardized precipitation evapotranspiration index (SPEI) revisited: parameter fitting, evapotranspiration models, tools, datasets and drought monitoring. International journal of climatology, pp. 3001-3023.

Chandrasekar, K., \& Sesha Sai, M. V. (2013). Monitoring of late-season agricultural drought in cotton growing districts of Andhra Pradesh state, India, using vegetation, water and soil moisture indices. Natural Hazards Journal of the International Society for the Prevention and Mitigation of Natural Hazards.

Das, P. K., Chakraborty, A., \& M. V. R., S. (2014). Spatial analysis of temporal trend of rainfall and rainy days during the Indian Summer Monsoon seasonusing daily gridded $\left(0.5^{\circ} \times\right.$ $0.5^{\circ}$ ) rainfall data for the period of 1971-2005. Royal Meteorological Society, pp. 481-493.

Das, P. K., Dutta, D., Sharma, J. R., \& Dadhwal, V. K. (2015). Trends and behaviour of meteorological drought (1901-2008) over Indian region using standardized precipitation evapotranspiration index. International journal of climatology.

Das, P. K., Midya, S. K., Das, D. K., Rao, G. S., \& Raj, U. (2017). Characterizing Indian meteorological moisture anomaly condition using long-term (1901-2013) gridded data: a multivariate moisture anomaly index approach. International Journal Of Climatology.

Dutta, D., Kundu, A., \& Patel, N. (2013). Predicting agricultural drought in eastern Rajasthan of India using. Taylor \& Francis, pp. 192-209.

Hao, Z., \& Aghakouchak, A. (2013). A Nonparametric Multivariate Multi-Index Drought Monitoring Framework. Advances of drought monitoring, pp. 89-101.

Hao, Z., \& AghaKouchak, A. (2013). Multivariate Standardized Drought Index: parametric multi-index model. Elsevier, 12-18.

Mishra, A. K., \& Singh, V. P. (2010). A review of drought concepts. Elsevier Journal of Hydrology, pp. 202-216.

Nicolai-Shaw, N., Zscheischler, J., Hirschi, M., Gudmundsson, L., \& Seneviratne, S. I. (2017). A drought event composite analysis using satellite remote sensing. Remote Sensing of Environment, pp. 216-225.

Rojas, O., Vrieling, A., \& Rembold, F. (2011). Assessing drought probability for agricultural areas in Africa with coarse resolution. Elsevier Remote Sensing of Environment, pp. 343352.

WenWang, Ertsen, M., Svoboda, M. D., \& Hafeez, M. (2016). Propagation of Drought: From Meteorological Drought to. Hindawi Publishing Corporation, 5. 